\title{
Surface modification and deuterium retention in reduced-activation steels exposed to low- energy, high-flux pure and helium-seeded deuterium plasmas
}

\author{
V.Kh. Alimov ${ }^{1,2,3}$, O.V. Ogorodnikova ${ }^{1 *}$, Y. Hatano ${ }^{2}$, Yu.M. Gasparyan ${ }^{1}$, V.S. Efimov ${ }^{1}$,

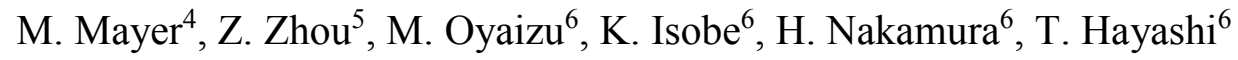 \\ ${ }^{1}$ National Research Nuclear University MEPhI (Moscow Engineering Physics Institute), Moscow \\ 115409, Russia \\ ${ }^{2}$ Hydrogen Isotope Research Center, Organization for Promotion of Research, University of Toyama, \\ Toyama 930-8555, Japan \\ ${ }^{3}$ A.N. Frumkin Institute of Physical Chemistry and Electrochemistry, Russian Academy of Sciences, \\ Moscow 119071, Russia \\ ${ }^{4}$ Max-Planck-Institut für Plasmaphysik, D-85748 Garching, Germany \\ ${ }^{5}$ University of Science and Technology Beijing, Beijing 100083, China \\ ${ }^{6}$ National Institutes for Quantum and Radiological Science and Technology, Rokkasho 039-3212, Japan
}

\begin{abstract}
Surface topography of and deuterium (D) retention in reduced activation ferritic-martensitic Eurofer'97 and ferritic oxide dispersion strengthening ODS-16Cr steels have been studied after exposure at $600 \mathrm{~K}$ to low-energy (70 and $200 \mathrm{eV})$, high-flux $\left(\sim 10^{22} \mathrm{D} / \mathrm{m}^{2} \mathrm{~s}\right)$ pure D and D$10 \% \mathrm{He}$ plasmas with $\mathrm{D}$ fluence of $2 \times 10^{25} \mathrm{D} / \mathrm{m}^{2}$. The methods used were scanning electron microscopy, energy-scanning $\mathrm{D}\left({ }^{3} \mathrm{He}, \mathrm{p}\right)^{4} \mathrm{He}$ nuclear reaction, and thermal desorption spectroscopy. As a result of the plasma exposures, nano-sized structures are formed on the steel surfaces. After exposure to pure D plasmas, a significant fraction of D is accumulated in the bulk, at depths larger than $8 \mu \mathrm{m}$. After exposures to D-He plasmas, D is retained mainly in the near-surface layers. In spite of the fact that the He fluence was lower than the D fluence, the He retention in the steels is one order of magnitude higher than the D retention.
\end{abstract}

Keywords: Deuterium retention, EUROFER'97 and 16Cr-ODS steels, Pure deuterium and helium-seeded deuterium plasmas, Surface morphology 
*Corresponding author at: National Research Nuclear University MEPhI (Moscow Engineering Physics Institute), Moscow 115409, Russia. Tel.: +7 (495) 788-56-99; fax: +7 (499) 324-21-11. E-mail address: olga@plasma.mephi.ru

\section{Introduction}

Reduced Activation Ferritic/Martensitic (RAFM) steels including Oxide Dispersion Strengthened Reduced Activation Ferritic/Martensitic and Ferritic steels (RAFM/RAF-ODS) are considered to be promising candidates for advanced fission and fusion structural materials $[1,2$, $3,4,5,6]$. The conventional RAFM and RAFM/RAF-ODS steels were developed to reduce the activation of structural materials and simplify special waste storage of fusion reactor components after service. With this objective, some alloying elements such as $\mathrm{Mo}, \mathrm{Nb}$ and $\mathrm{Ni}$ present in the commercial martensitic steels have been replaced by other elements which exhibit faster decay of induced radioactivity such as $\mathrm{Ta}, \mathrm{W}$, and $\mathrm{V}$ [7].

RAFM/RAF-ODS steels belong to the special group of steels with very good creep properties and oxidation resistance. This is due to the addition of $\mathrm{Y}_{2} \mathrm{O}_{3}$ nanoparticles, which stabilize the grain size and dislocation motion at elevated temperature [8].These ODS steels are also known as YWT alloys, since they contain Y, W and Ti particles. The $\mathrm{W}$ causes solid solution hardening, whereas the $\mathrm{Y}$ and $\mathrm{Ti}$ form complex mixed oxides and cause material strengthening [6].

In early papers $[2,9,10]$, RAFM steels were considered for use as the first wall and structural material for the DEMO reactor. At present, the most promising plasma-facing material for the main chamber wall of a fusion reactor is tungsten while RAFM and RAFM/RAF-ODS steels are considered as reference structural materials. Nevertheless, it was suggested to consider RAFM and RAFM/RAF-ODS steels as first wall materials in certain areas of the main chamber wall in DEMO where the particle and power flux are not prohibitive [11]. These certain areas will be mainly subjected to fluxes of energetic deuterium (D) and tritium (T) as well as helium $(\mathrm{He})$ particles at energies in the range from a few $\mathrm{eV}$ to several keV. Additionally, both plasmafacing and structural materials will be bombarded with $14 \mathrm{MeV}$ neutrons from the $\mathrm{D}-\mathrm{T}$ fusion reaction. 
Therefore, the evaluation of hydrogen isotope retention in undamaged and damaged RAFM and RAFM/RAF-ODS steels (i.e., in steels as-received and with ion-induced displacement damage simulating neutron-induced defects) is an important issue for safety assessment of fusion reactors.

In the last few years, experiments have provided a considerable database on the D retention in undamaged and damaged RAFM and RAFM/RAF-ODS steels irradiated with D ions and exposed to D plasmas [12, 13, 14, 15, 16, 17, 18, 19, 20, 21, 22, 23, 24, 25, 26, 27]. In Refs. [12$19,25,26]$, the D retention was studied with the help of thermal desorption spectrometry (TDS). However, the TDS technique provides only information about the total retention of hydrogen isotopes. In order to reveal what fractions of hydrogen isotopes are accumulated in the near surface layers and in the bulk of materials, measurements of hydrogen depth profiles are required. In Refs. [20-27], the depth distributions of D concentration in undamaged and damaged steels were determined by nuclear reaction analysis (NRA) at depths of up to several micrometers.

It has been reported recently $[22,24,25,28,29,30]$ that exposure of multicomponent RAFM and RAFM/RAF-ODS steels to low-energy (40-200 eV) deuterium plasmas with fluxes $>10^{19}$ ions $/ \mathrm{m}^{2} \mathrm{~s}$ leads to the formation of nano-structured near-surface layers enriched with $\mathrm{W}$. Along with the base medium- $Z$ (or mid- $Z$ ) iron (Fe), RAFM and RAFM/RAF-ODS steels contain typical mid- $Z$ steel-composing elements: Cr, V, Mn (conventional RAFM); Ti (RAFM/RAFODS) as well as 1-2 weight percents of high- $Z \mathrm{~W}$ (conventional RAFM and RAFM/RAF-ODS) and smaller amounts of high-Z Ta (conventional RAFM) and Y (RAFM/RAF-ODS). At low particle bombarding energy, the sputtering yield of the mid- $Z$ elements including $\mathrm{Fe}$ is significantly higher than that of high- $Z$ elements. As a result, the surface composition is changed due to preferential sputtering of mid- $Z$ elements, resulting in an enrichment of high- $Z$ elements at the surface. For example, a high concentration of tungsten is observed on tips of nano-sized fibers forming the nano-structured layer on the surface of the RAFM F82H steel [28]. As reported in Ref. [25], the exposure of EUROFER'97 and ODS steels to D plasma with D ion energy of $200 \mathrm{eV}$ (i.e., at $\mathrm{D}$ ion energy exceeding the sputtering threshold) results in a decrease in $\mathrm{D}$ retention. 
It should be noted that seeding of $\mathrm{He}$ ions into the $\mathrm{D}$ plasma reduces the $\mathrm{D}$ retention in RAFM steels F82H and Eurofer'97 as compared with that after exposure to a pure D plasma [19, 27].

In spite of intensive studies of D and He interaction with RAMF steels, the data are still scarce and there are uncertainties in the interpretation of the experimental data. Moreover, there is no direct comparison of data obtained under similar experimental conditions, and there is still a lack of understanding of the mechanisms of deuterium trapping in steels with different surface modifications. The objective of this work is to study the surface modification of and deuterium retention in conventional RAFM steel EUROFER'97 and RAF steel ODS-16Cr under exposure to low-energy, high-flux D and He-seeded D plasmas at the sample temperature of $600 \mathrm{~K}$. This temperature was chosen because the minimum temperatures of about $600 \mathrm{~K}$ and about $773 \mathrm{~K}$ are expected at the plasma-facing side of the RAFM steel used as first wall for Water Cooled Lithium Lead (WCLL) and Helium Cooled Pebble Bed (HCPB) blanket concepts of DEMO power reactor, respectively $[2-4,9,10]$. Therefore, the minimum sample temperature of $600 \mathrm{~K}$ was chosen to obtain data for assessment of expected maximum tritium retention in RAFM/RAF-ODS steels.

\section{Experimental}

Two types of reduced activation steels were used in this work: conventional RAFM steel EUROFER'97 (hereinafter EU'97) manufactured in the EU [3] and RAF-ODS steel ODS-16Cr manufactured in China [31]. The compositions of the EU'97 steel, in weight percent, is 0.09-0.12 C, 8.5-9.5 Cr, 1.0-1.2 W, 0.2-0.6 Mn, 0.15-0.25 V, 0.10-0.14 Ta, 0.015-0.045 N2, balance Fe [32]. The composition of the ODS-16Cr steel, in weight percent, is $0.008 \mathrm{C}, 15.5 \mathrm{Cr}, 1.67 \mathrm{~W}$, 0.19 Si, 0.49 Ti, 0.18 Y, 0.13 O, 0.47 N, balance Fe [33].

Rectangular-shaped EU'97and ODS-16Cr samples, $10 \times 10 \mathrm{~mm}^{2}$ in size, were cut from slabs of each material followed by mechanical polishing to a mirror-like finish and cleaning in an ultrasonic bath. The EU'97 samples were $1 \mathrm{~mm}$ thick, whereas a thickness of the ODS-16Cr samples was $0.5 \mathrm{~mm}$.

The steel samples (targets) were exposed to low-energy, high-flux pure and helium-seeded deuterium plasmas at a sample temperature of $600 \mathrm{~K}$. The linear plasma generator (LPG) used 
for producing plasma beams is described in Ref. [34]. Each of the steel samples was fixed on the LPG holder with the help of rings manufactured from 304 type stainless steel consists of (in weight percents) $18-20 \mathrm{Cr}, 8-12 \mathrm{Ni},<2 \mathrm{Mn}$, balance Fe.

To generate a pure $\mathrm{D}$ plasma, the $\mathrm{D}_{2}$ working pressure was kept at about $1 \mathrm{~Pa}$. As a result, a plasma beam with species of $\mathrm{D}_{2}{ }^{+}$(about $70 \%$ of the ion flux) and $\mathrm{D}^{+}$(about $30 \%$ ) was obtained. Bias voltages of -74 and $-204 \mathrm{~V}$ were applied to the samples, resulting in incident energies of 70 and $200 \mathrm{eV}$ for mixture of $\mathrm{D}_{2}{ }^{+}$and $\mathrm{D}^{+}$, respectively, taking into account the plasma potential of about $-4 \mathrm{~V}$ as measured by a Langmuir probe.

The incident $\mathrm{D}$ particle flux was fixed in the range from $0.8 \times 10^{22}$ to $1.2 \times 10^{22} \mathrm{D} / \mathrm{m}^{2} \mathrm{~s}$, whereas the D fluence was fixed at $2 \times 10^{25} \mathrm{D} / \mathrm{m}^{2}$. It should be noted that the $\mathrm{D}$ particle flux was calculated as the monitored D ion flux multiplied by 1.7 (i.e., $0.3+2 \times 0.7$ ). The $\mathrm{D}$ fluence was determined by integrating the $\mathrm{D}$ particle flux over the exposure time.

The required exposure temperature was set by the thermal contact between the sample and the water-cooled holder and by slight variation of the incident D ion flux. The temperature was monitored using a type $\mathrm{K}$ thermocouple tightly pressed to the rear of the sample. It should be noted that after plasma exposure termination, the sample temperature cooled down to $373 \mathrm{~K}$ in 5 $7 \mathrm{~min}$.

To generate a helium-seeded D plasma (D-He plasma), ${ }^{4} \mathrm{He}$ gas was injected into the plasma source region and the He partial pressure was kept at $10^{-1} \mathrm{~Pa}$. The concentration of $\mathrm{He}$ ions in the D-He plasma was about $10 \%$, as determined in separate experiments by measuring the sputtering yields of a W sample exposed to D-He plasmas with various He percentages [35]. Thus, the ion composition of the D-He plasma was determined to be $\mathrm{D}_{2}{ }^{+}$(about $63 \%$ ), $\mathrm{D}^{+}$(about $27 \%$ ), and $\mathrm{He}^{+}$(about 10\%). The samples were exposed to the D-He plasma to a D fluence of $2 \times 10^{25} \mathrm{D} / \mathrm{m}^{2}$.In these conditions the He fluence was estimated to be $1.3 \times 10^{24} \mathrm{He} / \mathrm{m}^{2}$.

The surface morphology of the steel samples exposed to the D and He-D plasmas was examined with a field-emission scanning electron microscope (SEM) JEOL JSM-6710F.

The deuterium depth profiles in the plasma-exposed samples were determined by nuclear reaction analysis (NRA) at IPP Garching. The $\mathrm{D}\left({ }^{3} \mathrm{He}, \mathrm{p}\right)^{4} \mathrm{He}$ reaction was utilized, and both the $\alpha$ particles and protons were analyzedat reaction angles of $102^{\circ}$ and $135^{\circ}$, respectively. To 
determine the $\mathrm{D}$ concentration at larger depths, an analyzing beam of ${ }^{3} \mathrm{He}$ ions with energies varied from 0.69 to $4.0 \mathrm{MeV}$ was used. This energy-scanning NRA technique allowed measurements of the D depth profiles to depths of $8 \mu \mathrm{m}$ [36]. The beam spot area was $\sim 1 \times 1 \mathrm{~mm}^{2}$ at normal incidence. For the deconvolution of the proton yields measured at different ${ }^{3} \mathrm{He}$ ion energies, the program SIMNRA [37] was used. A deuterium depth distribution was assumed taking into account the near-surface depth profile obtained from the $\alpha$ particle energetic spectrum, and the proton yield was calculated as a function of incident ${ }^{3} \mathrm{He}$ energy. The shape of the $\mathrm{D}$ depth profile was then varied using an iterative technique until the calculated curve matched the measured proton yields [36].

Tungsten depth profiles in the near-surface layers of the plasma-exposed steel samples were determined by means of Rutherford backscattering spectroscopy (RBS) [38] at ${ }^{3} \mathrm{He}$ ion energy of 3.2 MeV simultaneously with the NRA measurement. Thus, the $\mathrm{W}$ depth profiles were averaged over the surface area of $\sim 1 \times 1 \mathrm{~mm}^{2}$. The backscattered He particles were energyanalyzed at a scattering angle of $165^{\circ}$ by a small-angle surface barrier detector. The backscattered He spectrum was transformed into $\mathrm{W}$ depth profile using the program SIMNRA [37].

The retention of deuterium and helium in the plasma-exposed steel samples was measured by thermal desorption spectrometry (TDS). An ultra-high vacuum set-up equipped by two quadrupole mass spectrometers (QMS) for residual gas analysis - Pfeiffer Vacuum QME 200 and Hiden Hal 51- were used for the TDS measurements. A tungsten heater was used to heat the samples at a ramp rate of $2 \mathrm{~K} / \mathrm{s}$. After exposures to the D plasmas, molecules with mass 3 (HD) and mass $4\left(D_{2}\right)$ released during the TDS run were monitored by the Pfeiffer Vacuum QME 200 QMS. The absolute sensitivity of this QME 200 QMS was determined using calibrated leaks of $\mathrm{H}_{2}$ and $\mathrm{D}_{2}$. For the sensitivity of the mass 3 signal, the average of the sensitivities of mass 2 and mass 4 was taken.

For TDS detection of HD, $\mathrm{D}_{2}$ and He species after exposures to the D-He plasmas, both QMS, Pfeiffer Vacuum QME 200 and Hiden Hal 51, were used. The HD molecules were monitored by the Pfeiffer Vacuum QME 200 QMS, the $\mathrm{D}_{2}$ and He species (which both have mass 4) were detected by the Hiden Hal 51 QMS. The Hiden Hal 51 QMS can perform residual gas analysis at various energies of the ionizing electrons that allows to detect species with 
practically equal mass to charge ratios. According to the NIST Electron-Impact Cross Sections for Ionization and Excitation Database [39], values of the threshold ionization energies are $15.4 \mathrm{eV}$ for $\mathrm{D}_{2}$ and $24.5 \mathrm{eV}$ for He. During the TDS run, the $\mathrm{D}_{2}$ partial pressure signal was measured at an energy of the ionizing electrons of $19 \mathrm{eV}$, whereas the combined $\mathrm{D}_{2}$ and ${ }^{4} \mathrm{He}$ partial pressure signal was measured at $31 \mathrm{eV}$. The technique of threshold ionization mass spectrometry (TIMS) is described in details in Ref. [40]. The electron energies of 19 and $31 \mathrm{eV}$ were chosen for the somewhat arbitrary reason that they provided both reasonably approximate equivalent ionization cross sections for the two gases (deuterium and helium) and equivalent ionization cross section curve gradients. In addition to equal ionization cross sections, the chosen electron energies also have the optimum ion signal transmissions for both gases commensurate with equal ionization cross sections [40]. Standard $\mathrm{D}_{2}$ and He leaks with an accuracy better than $10 \%$ were employed to calibrate the Hiden Hal 51 QMS.

\section{Results and discussion}

\subsection{Surface morphology}

SEM images of EU'97 and ODS-16Cr samples exposed to the 70 and $200 \mathrm{eV}$ pure D and D-He plasmas at $600 \mathrm{~K}$ with the $\mathrm{D}$ fluence of $2 \times 10^{25} \mathrm{D} / \mathrm{m}^{2}$ demonstrate nano-sized fiber-like and coral-like structures formed on the steel surfaces (Figs. 1 and 2). Under exposures to the pure D and D-He plasmas, the EU'97 and ODS-16Cr surfaces are sputter-eroded since the energies of the incident ions (70 and $200 \mathrm{eV}$ ) exceed the threshold energies for sputtering of mid- $Z$ elements $[41,42]$. Besides, sputtering of the fixing rings manufactured from the 304 type stainless steel also takes place. The sputtered particles (mainly, Fe and Cr) cause the seeding of the plasma with mid- $Z$ ions that increases the sputtering rate of the EU'97 and ODS-16Cr steel samples.

After exposure to the $70 \mathrm{eV}$ pure D plasma, the morphology patterns of the nano-sized fiber-like structures formed on the EU'97 and ODS-16Cr surfaces are very similar (Fig. 1 a,b). The same statement is also valid for the structures formed on these steel surfaces after exposure to the $70 \mathrm{eV}$ D-He plasma (Fig. 2 a,b). However, seeding of He ions into the D plasma increases

the sputtering rate, and the nano-sized fiber-like structure becomes more pronounced after exposure to the $70 \mathrm{eV}$ D-He plasma than after exposure to the $70 \mathrm{eV}$ pure D plasma. 
A noticeable difference is observed in the morphology patterns formed on the EU'97 surface after exposures to $200 \mathrm{eV}$ pure D and D-He plasmas (Fig. $1 \mathrm{c}$ and Fig. 2 c). If elongated nano-sized structures consisting of tangled fibers are formed after exposure to the $200 \mathrm{eV}$ pure $\mathrm{D}$ plasma (Fig. 1 c), that fibers/cones are observed after exposure to the $200 \mathrm{eV}$ D-He plasma (Fig. 2 c).

Analysis of the plasma-exposed steel surfaces by the RBS technique (Fig. 3) indicates that the upper layers of the nano-sized structures are enriched in tungsten. Tungsten depth profiles in near-surface layers of the plasma-exposed steel samples, as evaluated from the RBS data assuming a dense homogeneous near-surface layer, are shown in Fig. 4.

After exposures to the 70 and $200 \mathrm{eV}$ pure D plasmas, the effective RBS-measured $\mathrm{W}$ concentration on the steel surfaces (averaged over a depth of about $20 \mathrm{~nm}$ and determined as the $\mathrm{W} /(\mathrm{Fe}+\mathrm{W}$ ) ratio) is estimated to be $2-3$ at.\% (Fig. 4 a). In turn, after exposures to the $70 \mathrm{eV}$ DHe plasmas, the effective RBS-measured $\mathrm{W}$ concentration on the steel surface reaches 4-6 at.\% (Fig. 4 b). It should be kept in mind, however, that these values were obtained assuming a smooth surface. Due to the general ambiguity between roughness and concentration depth profile the values should be treated with some care. However, the RBS results allow the conclusion that the $\mathrm{W}$ concentration maintained on the steel surface after exposures to the D-He plasmas is higher than that after exposures to the D plasmas. It can be also said that exposures with the 200 $\mathrm{eV}$ plasmas lead to deeper $\mathrm{W}$ enrichment into the bulk as compared to exposures with the $70 \mathrm{eV}$ plasmas (Fig. 4).

For the inhomogeneous-over surface fiber-like structures, the RBS technique can only provide averaged-over-surface value of the $\mathrm{W}$ concentration. As reported in Ref. [28], in the case of F82H steel exposed to $200 \mathrm{eV} \mathrm{D}$ plasma in the same linear plasma generator as used in the present study, only nano-sized fiber-like structures were enriched in tungsten. This observation was obtained with the help of cross-sectional energy dispersive X-ray (EDX) spectrometry. Moreover, the major part of $\mathrm{W}$ was observed on the top of the formed structures [28]. Therefore, it may be safely suggested that the $\mathrm{W}$ concentration in the nano-structures formed on the EU'97 and ODS-16Cr surfaces is higher than the effective RBS-measured W concentration.

Observations of nano-sized fiber-like structures formed on the RAFM and RAF-ODS steel surfaces subjected to the sputtering erosion were already reported in Refs. [25, 26, 28, 30]. Formation of the nano-sized structures can be explained by initial nucleation of high- $Z$ nano- 
sized crystallites under ion bombardment $[43,44]$. It is known $[45,46,47]$ that an impurity with lower sputtering yield or higher melting point than the target is prerequisite for a crystal to nucleate. The further growth of crystallites takes place on an ion-bombarded surface due to ionbombardment-induced diffusion of surface atoms (mainly, mid- $Z$ atoms), which is enhanced with increasing the target temperature [48, 49].

In the case of the EU'97 and ODS-16Cr samples exposed to the pure D and D-He plasmas, it may be suggested that at elevated concentration of high- $Z$ elements (mainly W) maintained in the outermost atomic layers at relatively low $\mathrm{D}$ fluence, high- $Z$ atoms form nano-sized agglomerations due to the plasma-induced and thermally-induced (at high temperatures) surface diffusion, and these high- $Z$ agglomerations serve as centers of nano-crystallite nucleation. The following growth of fiber-like structures due to the surface diffusion of mid- $Z$ atoms occurs under plasma exposure to higher fluences.

\subsection{Deuterium and helium retention}

In the EU'97 and ODS-16Crsamples exposed at $600 \mathrm{~K}$ to the 70 and $200 \mathrm{eV}$ pure D and DHe plasmas, the deuterium concentration in the near-surface layers ranges from $\sim 0.03$ to $\sim 0.7$ at.\%, depending on the plasma composition (Fig. 5). A higher near-surface D concentration observed after exposure to the D-He plasmas, as compared to that after the pure D plasma exposures, can be explained by additional trapping of D at surroundings of pressurized helium bubbles [13].

In the case of pure D plasma exposure, the D concentration in EU'97 samples at depths greater than $3 \mu \mathrm{m}$ is practically constant, equal to $(5-6) \times 10^{-5}$ at.\%, and does not depend on the energy of the D ions between 70 and $200 \mathrm{eV}$ (Fig. 5 a). However, the bulk D concentration has a maximum of $\sim 5 \times 10^{-4}$ at. $\%$ at a depth of $\sim 1.7 \mu \mathrm{m}$ in the ODS-16Cr sample and then decreasing into the bulk to be less than the detectable level of $1 \times 10^{-5}$ at.\% at depth greater than $4 \mu \mathrm{m}$ (Fig. 5 a). The high value of the concentration maximum can be probably explained by an existence of inhomogenious distribution in some particular samples of hydride-forming elements such as yttrium [50] and titanium [51] in the ODS-16Cr steel and high hydrogen trapping ability by those nanoparticles [52]. 
The concentration minimum observed in the steel samples exposed to the D plasmas at depths of 0.5-2 $\mu \mathrm{m}$ (Fig. $5 \mathrm{a}$ ) is thought to be explained by spontaneous release of deuterium at elevated temperatures after plasma exposure termination and depletion of the sub-surface layer in deuterium.

In the case of the D-He plasma exposure, the $\mathrm{D}$ concentration at depths greater than $1 \mu \mathrm{m}$ is even lower than $10^{-4}$ at.\% and cannot be accurately measured by the energy-scanning NRA technique due to the relatively high concentration of deuterium in the near-surface layers of the steels (Fig.5 b).

TDS spectra of deuterium released from steel samples exposed at $600 \mathrm{~K}$ to the 70 and 200 $\mathrm{eV}$ pure D plasmas (Fig. 6 a) demonstrate dominant peaks of about 700 and $950 \mathrm{~K}$ in the case of the ODS-16Cr sample and 800,920 and $1000 \mathrm{~K}$ in the case of the EU'97 samples. It is difficult to attribute these peaks to specific types of defects responsible for the $\mathrm{D}$ retention because of complicated surface modification under the sputtering/deposition processes. Although in all cases, W enrichment was observed on the surface, sub-surface compositions can be different for the ODS-16Cr and EU'97 samples as well as after the irradiation with different incident ion energies (70 and $200 \mathrm{eV}$ D plasmas) resulting in different dominant TDS peaks as one can see in Fig. 6a for the ODS-16Cr and EU'97 samples.

It was reported in Ref. [25] that in the case of exposure of the EU'97 and ODS-16Cr samples to D plasmas with an ion energy lower that the threshold energies for sputtering of the steel-composing elements, the D retention in the ODS- $16 \mathrm{Cr}$ sample is much higher than that in the EU'97 sample. However, in the case of the sputter-modified surface, especially at elevated temperatures, the difference in the D retention for the EU'97 and ODS-16Cr samples decreases. The present data confirm the importance of the effect of the surface nano-roughness formation on the D retention in steels compared to the steel structure and composition. As reported in Ref. [25], the formation of nano-sized structures on the ODS-9Cr and ODS-16Cr steel surfaces under exposure to D plasmas leads to a significant reduction in the total $\mathrm{D}$ retention due to an increase of the deuterium desorption flux. This is consistent with conclusion about the dominant role of the surface conditions in the $\mathrm{D}$ retention in steels reported in $[9,10]$. Moreover, a significant amount of $\mathrm{D}$ has penetrated through the present samples at present plasma conditions $[25,26]$. Because the ODS-16Cr sample $(0.5 \mathrm{~mm})$ is two times thinner than the EU' 97 sample $(1 \mathrm{~mm})$, the 
D retention in the ODS- $16 \mathrm{Cr}$ sample could be underestimated in comparison to the case of the same thicknesses of the EU'97 and ODS-16Cr samples.

TDS spectra of deuterium released from steel samples exposed to the He-seeded D plasmas at $600 \mathrm{~K}$ are shown in Fig. 6 b. Formation of nano-sized structures and He inclusions in the nearsurface layers in the case of D-He plasma exposures leads to complicated mechanisms of D trapping: the release of $\mathrm{D}$ starts at temperatures lower than the irradiation temperature. Comparing TDS from steels after the exposure to pure D and D+He plasmas, one can make conclusions about a reduction of the $\mathrm{D}$ retention at high temperature range but an increase of the $\mathrm{D}$ retention in low-temperature range after $\mathrm{D}+\mathrm{He}$ irradiation. Obviously, the intensity of 570 and $690 \mathrm{~K}$ peaks is higher than that of $980 \mathrm{~K}$ peak.

According to NRA data, the majority of $\mathrm{D}$ is trapped near the surface after D-He plasma exposures (Fig. 5b). It is reasonable to suggest that low-temperature release of $\mathrm{D}$ can be attributed to trapping of D by He clusters located near the surface. Since TDS starts already at $400 \mathrm{~K}$, which is below the irradiation temperature of $600 \mathrm{~K}$, we can suggest that soluble and weakly trapped $\mathrm{D}$ is re-distributed in defects with low binding energy for $\mathrm{D}$ after exposure to the plasma. In the case of pure D plasma, we did not observe such re-distribution of $\mathrm{D}$. This suggests the existence of many trapping sites for D with low binding energy, which can be He clusters with different sizes. This suggestion is supported by increasing the $\mathrm{D}$ retention at $200 \mathrm{eV} \mathrm{D}+\mathrm{He}$ plasma exposure compared to $70 \mathrm{eV} \mathrm{D}+\mathrm{He}$ plasma exposure because of the increase of the $\mathrm{He}$ retention in EU'97 steel as shown in Table 1.

Table 1 shows the D retention in EU'97 and ODS-16Cr steels measured by NRA and TDS and the He retention measured by TDS. The D retention in EU'97 and ODS-16Cr steels exposed at $600 \mathrm{~K}$ to low-energy, high flux $\mathrm{D}$ and He-seeded D plasmas is low $\left(\leq 3 \times 10^{19} \mathrm{D} / \mathrm{m}^{2}\right)$. The reasons for it are (i) enhanced desorption of D from sputter-modified surface, (ii) considerable amount of $\mathrm{D}$ has penetrated through the present samples with $0.5-1 \mathrm{~mm}$ of the thickness $[25,26]$ and (iii) potentially outgassing between the different measurements [53]. Note that due to the low amount of retained deuterium $\left(\leq 3 \times 10^{19} \mathrm{D} / \mathrm{m}^{2}\right)$, errors in the energy-scanning NRA and TDS measurements can reach $50 \%$ or even higher. From the comparison of the TDS and NRA data obtained after exposure of the steel samples at $600 \mathrm{~K}$ to the 70 and $200 \mathrm{eV}$ pure D plasmas it is 
clear that a significant fraction of deuterium is accumulated in the bulk, at depths greater than 8 $\mu \mathrm{m}$.

A systematic reduction in the $\mathrm{D}$ retention after $\mathrm{D}+\mathrm{He}$ plasma exposure compared to pure $\mathrm{D}$ plasma exposure was observed (see Table 1). The energy-scanning NRA and TDS results obtained after exposures to the 70 and $200 \mathrm{eV}$ He-seeded D plasmas allow us to draw the conclusion that deuterium is retained mainly in the near-surface layers, and the fraction of deuterium retained in the bulk is negligible. A similar effect was observed in the case of F82H steel [19] as well as in the case of W exposed to pure D and D-He plasmas [35, 54]: seeding of helium ions into the $\mathrm{D}$ plasma significantly reduces the $\mathrm{D}$ retention in $\mathrm{W}$ at temperatures above $400 \mathrm{~K}$. Due to trapping of D with He clusters, the soluble concentration of D, which is the driving force for the diffusion, is decreased in the bulk, thus, reducing the D diffusion into the bulk. Moreover, the diffusion coefficient can be enhanced in the near-surface region due to (i) the strain field induced by $\mathrm{He}$ bubbles [54,55] and (ii) interconnection of helium bubbles providing return pathways for inward diffusing $\mathrm{D}$ back to the surface $[35,55]$ that are additional reasons for the reduction of the D diffusion into the bulk of the EU'97 and ODS-16Cr samples during exposure to the D-He plasmas.

Despite the fact that the He flux was about 10 times lower than the D flux, the He retention is one order of magnitude higher than the D retention in steels (Table 1). TDS spectra of He released from the steel samples exposed to D-He plasmas are described by curves with multiple peaks (Fig. 6 c). These TDS peaks can be related to the He desorption from various helium complexes. TDS of $\mathrm{He}$ also starts at a temperature below the irradiation temperature similar to the case of the D release from steels after the exposure to D+He plasma (Fig. 6b). This observation confirms the assumption about the existence of a range of binding energies of $\mathrm{He}$ and formation of He clusters with different sizes.

\section{Conclusions}

Samples prepared from reduced activation ferritic/martensitic EU'97 and ferritic oxide dispersion strengthening ODS-16Cr steels have been exposed at $600 \mathrm{~K}$ to low-energy (70 and $200 \mathrm{eV})$, high-flux $\left(\sim 10^{22} \mathrm{D} / \mathrm{m}^{2} \mathrm{~s}\right)$ pure D and D- $10 \% \mathrm{He}$ plasmas with a D fluence of $2 \times 10^{25}$ $\mathrm{D} / \mathrm{m}^{2}$. 
Practically no difference in the morphology patterns of the nano-sized fiber-like structures formed on the EU'97 and ODS-16Cr surfaces was observed after the exposure to the $70 \mathrm{eV}$ either pure D or He-seeded D plasmas. In the case of exposure to the D-He plasma, higher $\mathrm{W}$ near-surface concentration was detected both for the EU'97 and ODS-16Cr samples due to a higher sputtering yield of low- and mid- $Z$ steel-composing elements from the steel surface by more heavy $\mathrm{He}$ ions compared to lighter $\mathrm{D}$ ions in the case of exposure to the pure $\mathrm{D}$ plasma. However, noticeable difference was observed in the morphology patterns formed on the EU'97 surface after exposures to the plasmas with higher ion energy: elongated nano-sized structures consisting of tangled fibers were formed in the case of exposure to the $200 \mathrm{eV}$ pure D plasma, whereas nano-sized fibers/cones were observed after exposure to the $200 \mathrm{eV}$ D-He plasma.

After irradiation with the 70 and $200 \mathrm{eV}$ pure D plasma at $600 \mathrm{~K}$, the D retention in the EU'97 and ODS-16Cr samples is low $\left(\leq 3 \times 10^{19} \mathrm{D} / \mathrm{m}^{2}\right)$. As it was already reported in [25], the surface roughness with $\mathrm{W}$ enrichment caused by preferential sputtering of mid- $Z$ steelcomposing elements accompanied by radiation-induced diffusion and segregation of surface atoms significantly decreases the $\mathrm{D}$ retention due to an increase of the $\mathrm{D}$ desorption flux. Moreover, a significant part of $\mathrm{D}$ is penetrating through the steel samples under the present irradiation conditions and can be also released between measurements. No significant difference between the D retention in the EU'97 and ODS-16Cr steels was observed after exposure to the $70 \mathrm{eV} \mathrm{D}$ plasma at $600 \mathrm{~K}$ indicating that the nano-structured surface roughness has the dominating effect on the D retention at elevated temperatures compared to the steel structure and composition.

Seeding of $\mathrm{He}$ ions into the D plasma, apart from enhancing the sputtering and, consequently, enhancing the $\mathrm{W}$-enriched surface roughness, results in a further decrease of the $\mathrm{D}$ retention due to reduction of the $\mathrm{D}$ diffusion flux into the bulk. Despite the low fraction of $\mathrm{He}$ ions in the D-He plasma ( $10 \%)$, the He retention in the EU'97 and ODS-16Cr steels is one order of magnitude higher than the $\mathrm{D}$ retention.

\section{Acknowledgements}

The authors gratefully acknowledge J. Dorner and M Fußeder (Max-Planck-Institut für Plasmaphysik, Garching, Germany) for their technical assistance. This work was partly 
supported by JAEA (Joint Work contract \#27K422), as a part of Broader Approach activities, and partly supported by the Russian Science Foundation (RSF), Grant № 16-12-10332. 


\section{Figure captions}

Figure 1. SEM images of the EUROFER'97 and ODS-16Cr samples exposed at $600 \mathrm{~K}$ to 70 and $200 \mathrm{eV}$ D plasmas with the D fluence of $2 \times 10^{25} \mathrm{D} / \mathrm{m}^{2}$. The scale bar given in panel (b) is valid for all images.

Figure 2. SEM images of the EUROFER'97 and ODS-16Cr samples exposed at $600 \mathrm{~K}$ to 70 and $200 \mathrm{eV}$ He-seeded D plasmas with the D fluence of $2 \times 10^{25} \mathrm{D} / \mathrm{m}^{2}$. The scale bar given in panel (b) is valid for all images.

Figure 3. Rutherford backscattering (RBS) spectra for $3.2 \mathrm{MeV}^{3} \mathrm{He}$ ions incident on the EUROFER'97 and ODS-16Cr samples exposed at $600 \mathrm{~K}$ to 70 and $200 \mathrm{eV}$ D plasmas (a) and He-seeded D plasmas (b) with the D fluence of $2 \times 10^{25} \mathrm{D} / \mathrm{m}^{2}$. An analyzing dose of $5 \mu \mathrm{C}$ was collected for each measurement. The W peak indicates the surface enrichment of $\mathrm{W}$ while the backscattering level at lower energies corresponds to the $\mathrm{W}$ bulk concentration. The lines represent RBS spectra calculated by the SIMNRA program [37].

Figure 4. W depth profiles in the near-surface layers of EUROFER'97 and ODS-16Cr samples exposed at $600 \mathrm{~K}$ to 70 and $200 \mathrm{eV}$ D plasmas (a) and He-seeded D plasmas (b) with the D fluence of $2 \times 10^{25} \mathrm{D} / \mathrm{m}^{2}$, as measured by the RBS technique (Fig. 3) and evaluated by the SIMNRA program [37]. Arrows indicate depths calculated using the atomic density of pure Fe. Note that the $\mathrm{W}$ depth profiles are averaged over the surface area of $\sim 1 \times 1 \mathrm{~mm}^{2}$.

Figure 5. Depth profiles of deuterium retained in EUROFER'97 and ODS-16Cr samples exposed at $600 \mathrm{~K}$ to 70 and $200 \mathrm{eV}$ D plasmas (a) and He-seeded D plasmas (b) with the D fluence of $2 \times 10^{25} \mathrm{D} / \mathrm{m}^{2}$, as measured by the energy-scanning NRA technique. Note that the D depth profiles are averaged over the surface area of $\sim 1 \times 1 \mathrm{~mm}^{2}$.

Figure 6.Thermal desorption spectra of deuterium $(\mathrm{a}, \mathrm{b})$ and helium (c) released from EUROFER'97 and ODS-16Cr samples exposed at $600 \mathrm{~K}$ to 70 and $200 \mathrm{eV}$ D plasmas (a) and He-seeded D plasmas $(b, c)$ with the D fluence of $2 \times 10^{25} \mathrm{D} / \mathrm{m}^{2}$. The TDS heating rate was $2 \mathrm{~K} / \mathrm{s}$. 
Table 1. Deuterium and helium retention in EUROFER'97 and ODS-16Cr samples exposed at $600 \mathrm{~K}$ to 70 and $200 \mathrm{eV}$ D plasmas and D-He plasmas with the D fluence of $2 \times 10^{25} \mathrm{D} / \mathrm{m}^{2}$, as measured by the energy-scanning NRA and TDS techniques.

\begin{tabular}{|l|c|c|c|}
\hline & D ret., NRA & D ret., TDS & He ret., TDS \\
\hline $70 \mathrm{eV}$ D plasma $\rightarrow$ EU'97 & $1.1 \times 10^{18} \mathrm{D} / \mathrm{m}^{2}(0-8 \mu \mathrm{m})$ & $1.9 \times 10^{19} \mathrm{D} / \mathrm{m}^{2}$ & - \\
\hline $70 \mathrm{eV}$ plasma D $\rightarrow$ ODS-16Cr & $1.7 \times 10^{18} \mathrm{D} / \mathrm{m}^{2}(0-8 \mu \mathrm{m})$ & $7.6 \times 10^{18} \mathrm{D} / \mathrm{m}^{2}$ & - \\
\hline $200 \mathrm{eV}$ D plasma $\rightarrow$ EU'97 & $2.8 \times 10^{18} \mathrm{D} / \mathrm{m}^{2}(0-8 \mu \mathrm{m})$ & $1.5 \times 10^{19} \mathrm{D} / \mathrm{m}^{2}$ & - \\
\hline $70 \mathrm{eV}$ D-He plasma $\rightarrow$ EU'97 & $1.8 \times 10^{19} \mathrm{D} / \mathrm{m}^{2}(0-0.5 \mu \mathrm{m})$ & $6.7 \times 10^{18} \mathrm{D} / \mathrm{m}^{2}$ & $1.4 \times 10^{20} \mathrm{He} / \mathrm{m}^{2}$ \\
\hline $70 \mathrm{eV}$ plasma D-He $\rightarrow$ ODS-16Cr & $1.7 \times 10^{19} \mathrm{D} / \mathrm{m}^{2}(0-0.5 \mu \mathrm{m})$ & $7.4 \times 10^{18} \mathrm{D} / \mathrm{m}^{2}$ & $2.0 \times 10^{20} \mathrm{He} / \mathrm{m}^{2}$ \\
\hline $200 \mathrm{eV}$ D-He plasma $\rightarrow$ EU'97 & $3.0 \times 10^{19} \mathrm{D} / \mathrm{m}^{2}(0-0.5 \mu \mathrm{m})$ & $9.8 \times 10^{18} \mathrm{D} / \mathrm{m}^{2}$ & $2.8 \times 10^{20} \mathrm{He} / \mathrm{m}^{2}$ \\
\hline
\end{tabular}



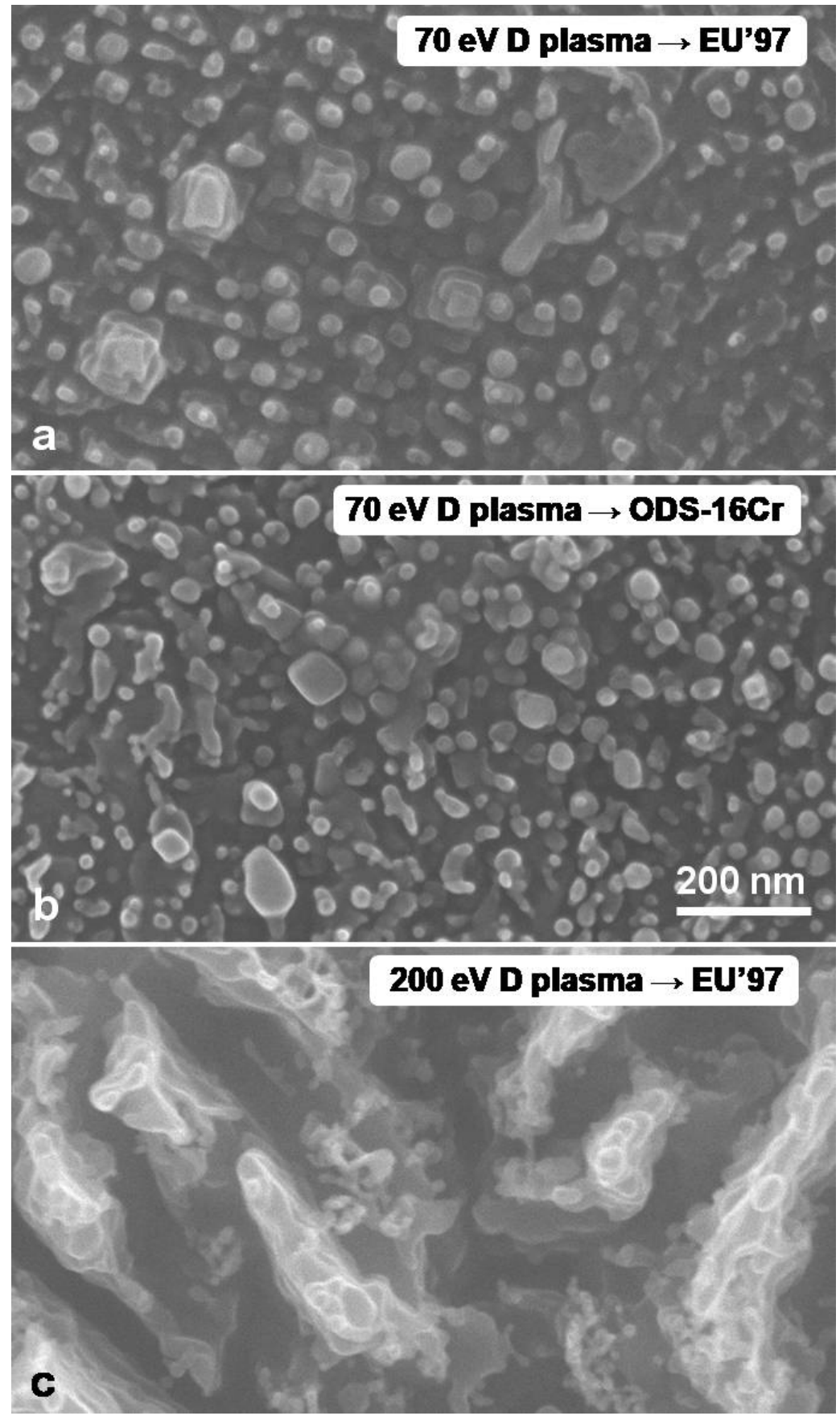

Figure 1. 

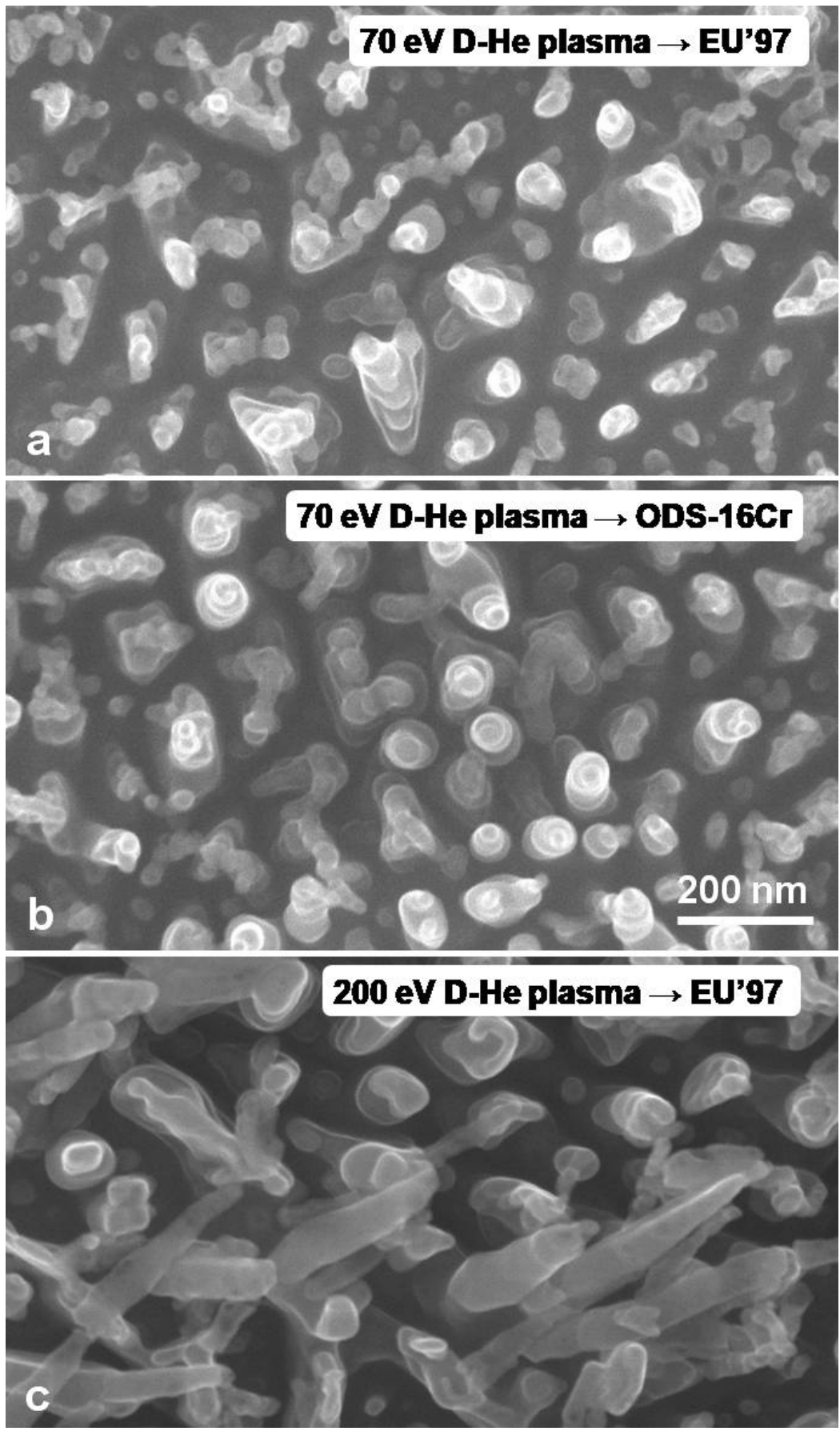

Figure 2. 

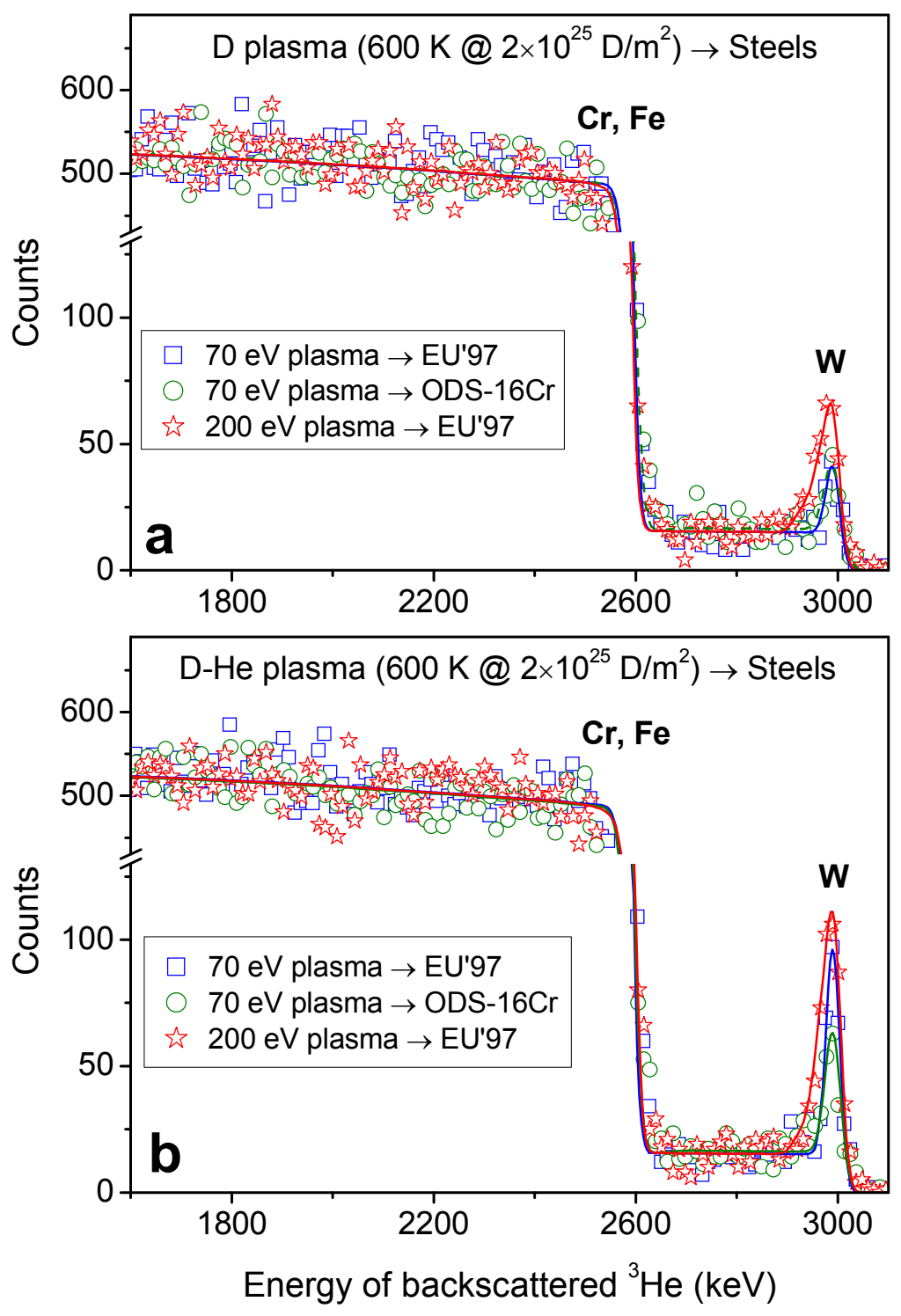

Figure 3. 

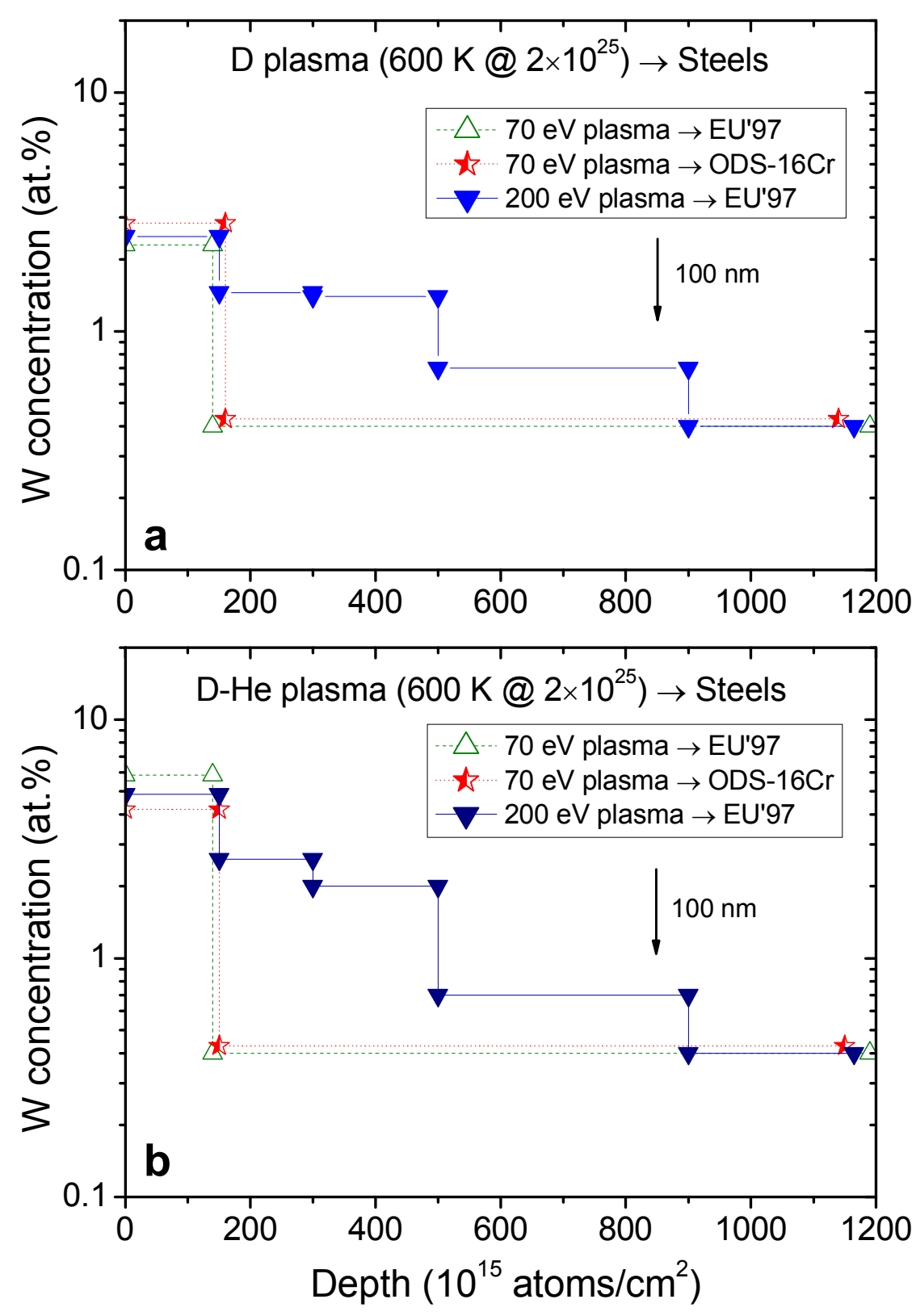

Figure 4. 

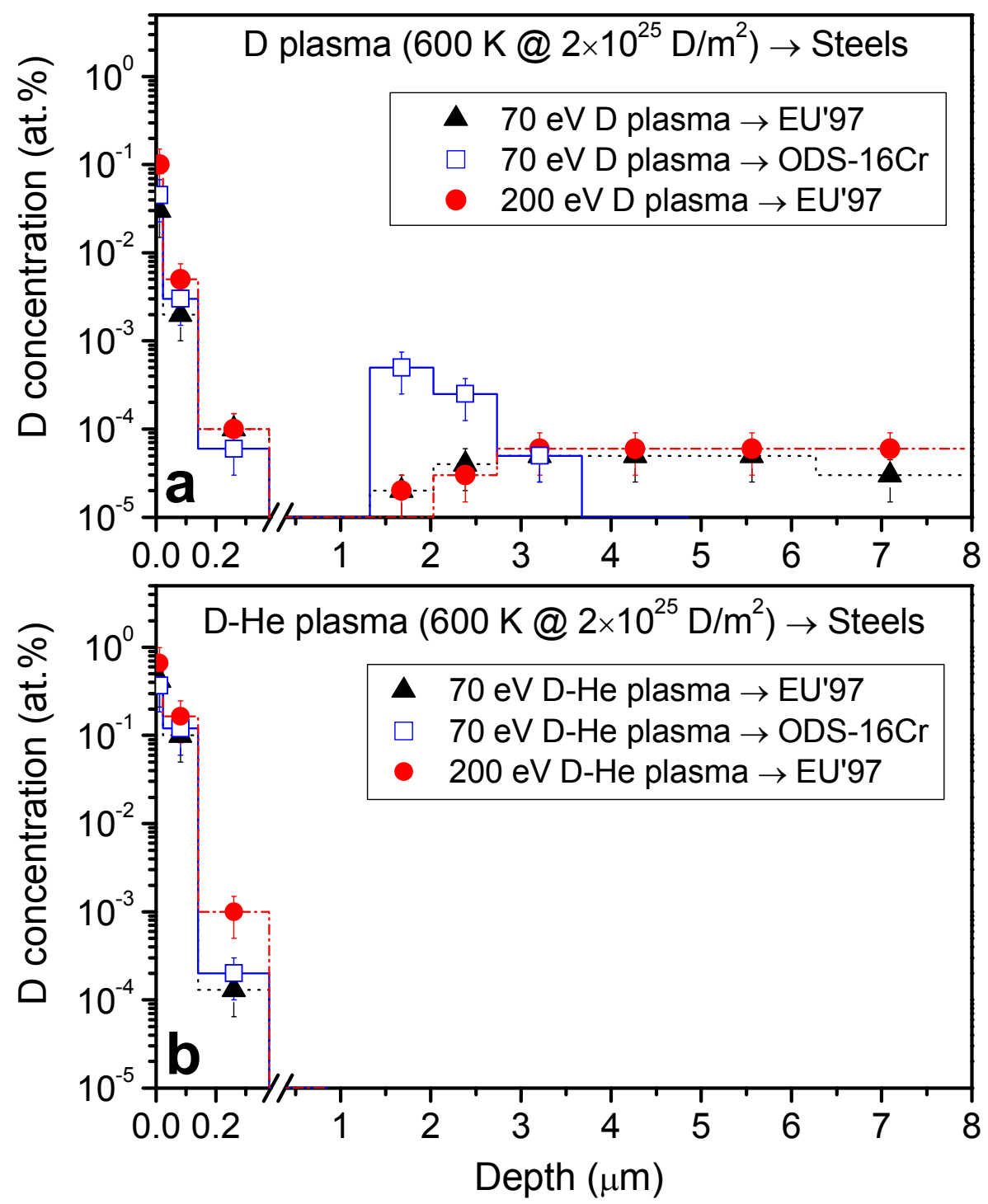

Figure 5. 

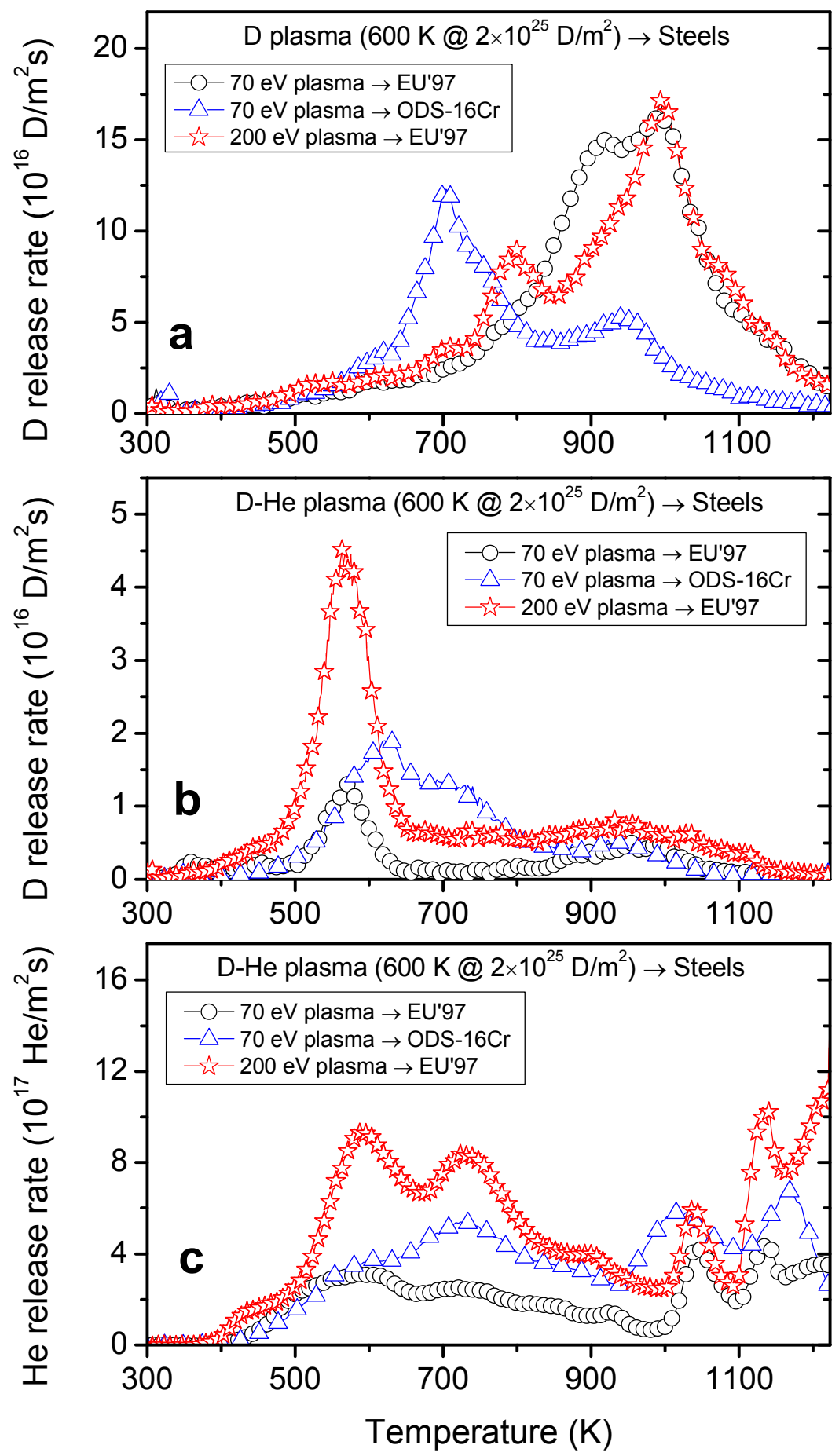

Figure 6. 


\section{References}

[1] A. Hishinuma, A. Kohyama, R.L. Klueh, D.S. Gelles, W. Dietz, K. Ehrlich, J. Nucl. Mater. 258-263 (1998)193.

[2] M.A. Fütterer, L. Barleon, L. Giancarli, A. Li Puma, O.V. Ogorodnikova, Y. Poitevin, J.F. Salavy, J. Szczepanski, G. Vella, Fusion Eng. Des. 49-50 (2000) 543.

[3] B. van der Schaaf, F. Tavassoli, C. Fazio, E. Rigal, E. Diegele, R. Lindau, G. LeMarois,Fusion Eng. Des.69 (2003) 197.

[4] N. Baluc, R. Schäublin, P. Spätig, M. Victoria, Nucl. Fusion 44 (2004) 56.

[5] M. Klimenkov, R. Lindau, A. Möslang, J. Nucl. Mater. 386-388 (2009) 553.

[6] S. Ukai, S. Ohtsuka, T. Kaito, H. Sakasegawa, N. Chikata, S. Hayashi, S. Ohnuki, Mater. Sci. Eng. A 510-511 (2009) 115.

[7] A. Kohyama, A. Hishinuma, D.S. Gelles, R.L. Klueh, W. Dietz, K. Ehrlich, J. Nucl. Mater. 233-237 (1996) 138.

[8] D.T. Hoelzer, B.A. Pint, I.G. Wright, J. Nucl. Mater. 283-287 (2000) 1306.

[9] O.V. Ogorodnikova, M.A. Fütterer, E. Serra, G. Benamati, J.-F. Salavy, G. Aiello, J. Nucl. Mater. 273 (1999) 66.

[10] O.V. Ogorodnikova, X. Raepsaet, M.A. Fütterer, Fusion Eng. Des. 49 (2000) 921.

[11] B.J. Braams, K. Lim, IAEA Nuclear Data Section, Plasma-Material Interaction with Steel Surfaces. Summary Report of a Consultancy Meeting, Vienna, August 20, 2014, https://wwwnds.iaea.org/publications/indc/indc-nds-0671.pdf.

[12] Y. Yamauchi, Y. Hirohata, T. Hino, J. Nucl. Mater. 363-365 (2007) 984.

[13] D. Hamaguchi, H. Iwakiri, T. Kawamura, H. Abe, T. Iwai, K. Kikuchi, N. Yoshida, J. Nucl. Mater. 386-388 (2009) 375.

[14] T. Hino, Y. Katada, Y. Yamauchi, M. Akiba, S. Suzuki, T. Ezato, J. Nucl. Mater. 386-388 (2009) 736.

[15] Y. Yamauchi, K. Gotoh, Y. Nobuta, T. Hino, S. Suzuki, M. Akiba, Fusion Eng. Des. 85 (2010) 1838.

[16] T. Ito, Y. Yamauchi, T. Hino, T. Shibayama, Y. Nobuta, K. Ezato, S. Suzuki, M. Akiba, J. Nucl. Mater. 417 (2011) 1147. 
[17] G.D. Tolstolutskaya, V.V. Ruzhytskyi, V.N. Voyevodin, I.E. Kopanets, S.A. Karpov, A.V. Nikitin, J. Nucl. Mater. 442 (2013) S710.

[18] N. Shinoda, Y. Yamauchi, Y. Nobuta, J. Nucl. Mater. 463 (2015) 1001.

[19] K. Yakushiji, H.T. Lee, M. Oya, Y. Hamaji, K. Ibano, Y. Ueda, Phys. Scr. T 167 (2016) 014067.

[20] I. Takagi, T. Komura, M. Akiyoshi, K. Moritani, T. Sasaki, H. Moriyama, J. Nucl. Mater. 442 (2013) S33.

[21] O.V. Ogorodnikova, K. Sugiyama, J. Nucl. Mater. 442 (2013) 518.

[22] V.Kh. Alimov, Y. Hatano, K. Sugiyama, M. Balden, T. Höschen, M. Oyaidzu, J. Roth,

J. Dorner, M. Fußeder, T. Yamanishi, Phys. Scr. T159 (2014) 014049.

[23] V.Kh. Alimov, Y. Hatano, K. Sugiyama, S. Kondo, T. Hinoki, M. Tokitani, Fusion Eng. Des. 113 (2016) 336.

[24] N. Ashikawa, K. Sugiyama, A. Manhard, M. Balden, W. Jacob, Fusion Eng. Des. 112 (2016) 236.

[25] O.V. Ogorodnikova, Z. Zhou, K. Sugiyama, M. Balden, Yu. Gasparyan, V. Efimov, Nucl. Fusion 57 (2017) 036010.

[26] O.V. Ogorodnikova, Z. Zhou, K. Sugiyama, M. Balden, G. Pinstuk, Yu. Gasparyan, V. Efimov, Nucl. Fusion 57 (2017) 036011.

[27] Y. Martynova, S. Möller, M. Rasiński, D. Matveev, M. Freisinger, K. Kiss, A. Kreter, B. Unterberg, S. Brezinsek, Ch. Linsmeier, Nucl. Mater. Ener. (2017) http://dx.doi.org/10.1016/j.nme.2017.05.005

[28] V.Kh. Alimov, Y. Hatano, N. Yoshida, H. Watanabe, M. Oyaidzu, M. Tokitani, T. Hayashi, Nucl. Mater. Energy 7 (2016) 25.

[29] J. Roth, K. Sugiyama, V. Alimov, T. Höschen, M. Baldwin, R. Doerner, J. Nucl. Mater. 454 (2014) 1.

[30] M. Balden, S. Elgeti, M. Zibrov, K. Bystrov, T.W. Morgan, Nucl. Mater. Energy (2017), http://dx.doi.org/10.1016/j.nme.2017.01.001.

[31] S. Li, Z. Zhou, M. Wang, H. Hu, L. Zou, G. Zhang,L. Zhang, J. Phys. Conf. Ser.419 (2013) 012036. 
[32] R. Lindau, A. Möslang, M. Rieth, M. Klimiankou, E. Materna-Morris, A. Alamo, A.A.F. Tavassoli, C. Cayron, A.-M. Lancha, P. Fernandez, N. Baluc, R. Schäublin, E. Diegele, G. Filacchioni, J.W. Rensman, B.v.d. Schaaf, E. Lucon, W. Dietz, Fusion Eng. Des. 75-79 (2005) 989.

[33] S. Li, Z. Zhou, J. Jang, M. Wang, H. Hu, H. SunZou, G. Zhang, L. Zhang,J. Nucl. Mater. 455 (2014) 194.

[34] G.-N. Luo, W.M. Shu, H. Nakamura, S. O'Hira, M. Nishi, Rev. Sci. Instrum. 75 (2004) 4374.

[35] V.Kh. Alimov, W.M. Shu, J. Roth, K. Sugiyama, S. Lindig, M. Balden, K. Isobe, T. Yamanishi, Phys. Scr. T138 (2009) 014048.

[36] V.Kh. Alimov, M. Mayer, J. Roth, Nucl. Instr. Meth. B 234 (2005) 169.

[37] M. Mayer, SIMNRA User's Guide, Tech. Rep. IPP 9/113, Max-Planck-Institut für Plasmaphysik, Garching, 1997,home.mpcdf.mpg.de/ mam/

[38] W.K. Chu, J.W. Mayer, M.A. Nicolet, Backscattering Spectrometry, Academic Press, 1978.

[39] Y.-K. Kim, K.K. Irikura, M.E. Rudd, M.A. Ali, P.M. Stone, J. Chang, J.S. Coursey, R.A. Dragoset, A.R. Kishore, K.J. Olsen, A.M. Sansonetti, G.G. Wiersma, D.S. Zucker, M.A. Zucker, Electron-Impact Ionization Cross Section for Ionization and Excitation Database (version 3.0), National Institute of Standards and Technology, Gaithersburg, MD., 2004,http://physics.nist.gov/ionxsec

[40] S. Davies, J.A. Rees, D.L. Seymour, Vacuum 101 (2014) 416.

[41] W. Eckstein, C. Garćia-Rosales, J. Roth, W. Ottenberger, Sputtering Data, Report IPP 9/82, Max-Planck-Institut für Plasmaphysik, Garching, 1993.

[42] K. Sugiyama, K. Schmid, W. Jacob, Nucl. Mater. Energy 8 (2016) 1.

[43] G.K. Wehner, Appl. Phys. Lett. 43 (1983) 366.

[44] G.K. Wehner, J. Vac. Sci. Technol. A 3 (1985) 1821

[45] A. Maekawa, F. Okuyama, Surf. Sci. Lett. 481 (2001) L427.

[46] J.D. Weeks and G.H. Gilmer, in: I. Prigogine and S.A. Rice (Eds.), Advances in Chemical Physics, Vol. 40, Wiley, New York, 1979, pp. 157-228.

[47] W.R. Hudson, J. Vac. Sci. Technol. 14 (1977) 286. 
[48] R.S. Robinson, M.S. Rossnagel, J. Vac. Sci. Technol. 21 (1982) 790.

[49] T. Michely, G. Comsa,Nucl. Instrum. Meth. B 82 (1993) 207.

[50] D. Khatamian, F.D. Manchester, Bull. Alloy Phase Diagr. 9 (1988) 252.

[51] A. San-Martin, F.D. Manchester, Bull. Alloy Phase Diagr. 8 (1987) 30.

[52] E. Malitckii, Yu. Yagodzinskyy, H. Hänninen, Fusion Eng. Des. 98-99 (2015) 2025.

[53] S.A. Ryabtsev, Yu.M. Gasparyan, Z.R. Harutyunyan, I.M. Timofeev, O.V. Ogorodnikova, A.A. Pisarev, Phys. Scr.T170 (2017) 014016.

[54] O.V. Ogorodnikova,T. Schwarz-Selinger, K. Sugiyama, V.Kh. Alimov, J. Appl. Phys. 109 (2011) 013309.

[55] M.J. Baldwin, R.P. Doerner, W.R. Wampler, D. Nishijima, T. Lynch, M. Miyamoto, Nucl. Fusion 51 (2011) 103021. 